\title{
Iris coloboma, ptosis, hypertelorism, and mental retardation: a new syndrome possibly localised on chromosome 2
}

\author{
R Pallotta
}

\begin{abstract}
A patient with a phenotype resembling that of three children recently reported is described. His karyotype shows a pericentric inversion of chromosome 2 , very similar to another child previously reported. We discuss the possibility that all these cases constitute a distinct syndrome.
\end{abstract}

In 1983 we described a child aged 4 years with unusual facial features including bilateral ptosis, oedematous upper eyelids, hypertelorism, epicanthic folds, bilateral iris coloboma, a broad nasal tip, long philtrum, large mouth with a thin upper lip, pterygium, and mental and motor retardation. 'His karyotype showed a pericentric inversion of chromosome 2 . Earlier a child had been reported by Aymé $e t a l^{2}$ with motor retardation, a very similar facies, and an identical chromosomal rearrangement. The possibility of a distinct syndrome arose. ${ }^{3}$

Baraitser and Winter ${ }^{4}$ recently reported a new syndrome in three children with very similar characteristics. Therefore, there is a possibility that all these cases comprise a unique syndrome and we propose a possible aetiology.

\section{Case report}

A 6 year old male was born after a normal pregnancy to a non-consanguineous, 32 year old Italian female and a 46 year old male. His birth weight was $3100 \mathrm{~g}$

Istituto di Pediatria e Ostetricia, Ospedale Pediatrico, Via Discesa Delle Carceri 2, 66100 Chieti, Italy.

R Pallotta

Received for publication 28 June 1990.

Revised version accepted for publication 14 September 1990. and there were no perinatal problems. Persistent hypertrichosis and his unusual appearance led to the examination of his karyotype and to a psychomotor examination (Gesell). The latter investigation was normal. When he was 21 months old, a new psychomotor test (Brunet-Levine) indicated global retardation that particularly involved his speech. A CT scan of the head showed hypoplasia of the anterior pits. On examination, the child had a persistent metopic ridge, ptosis and oedema of the upper eyelid, epicanthic folds, telecanthus, hypertelorism, bilateral coloboma of the iris and choroid reaching the optic nerve inferiorly, a broad nasal tip, long philtrum, large mouth with thin upper lip, full cheeks, pointed chin, short neck, pterygium, low posterior hairline, and cryptorchidism (figure).

Height, weight, and head circumference were all below the 3rd centile. The karyotype, stained by QFQ banding, was 46,XY,inv(2)(pl2q14). The chromosomal rearrangement had been inherited from his mother, who was phenotypically normal.

\section{Discussion}

The case reported here is similar to those described by Baraitser and Winter. ${ }^{4}$ All had coloboma of the iris, ptosis, hypertelorism, epicanthic folds, mental and motor retardation, and short stature.

A comparison of the photographs (table) supported the similarities, ${ }^{4}$ and showed oedematous upper eyelids, long philtrum, large mouth with thin upper lip, full cheeks, and pointed chin. The possible presence of a broad nasal tip may complete the characteristics. Moreover, our case and case 3 of Baraitser and Winter ${ }^{4}$ both have a short neck with pterygium and low posterior hairline.

The facies is similar to the 17 month old child described by Aymé et al, ${ }^{2}$ reported as having a moon 


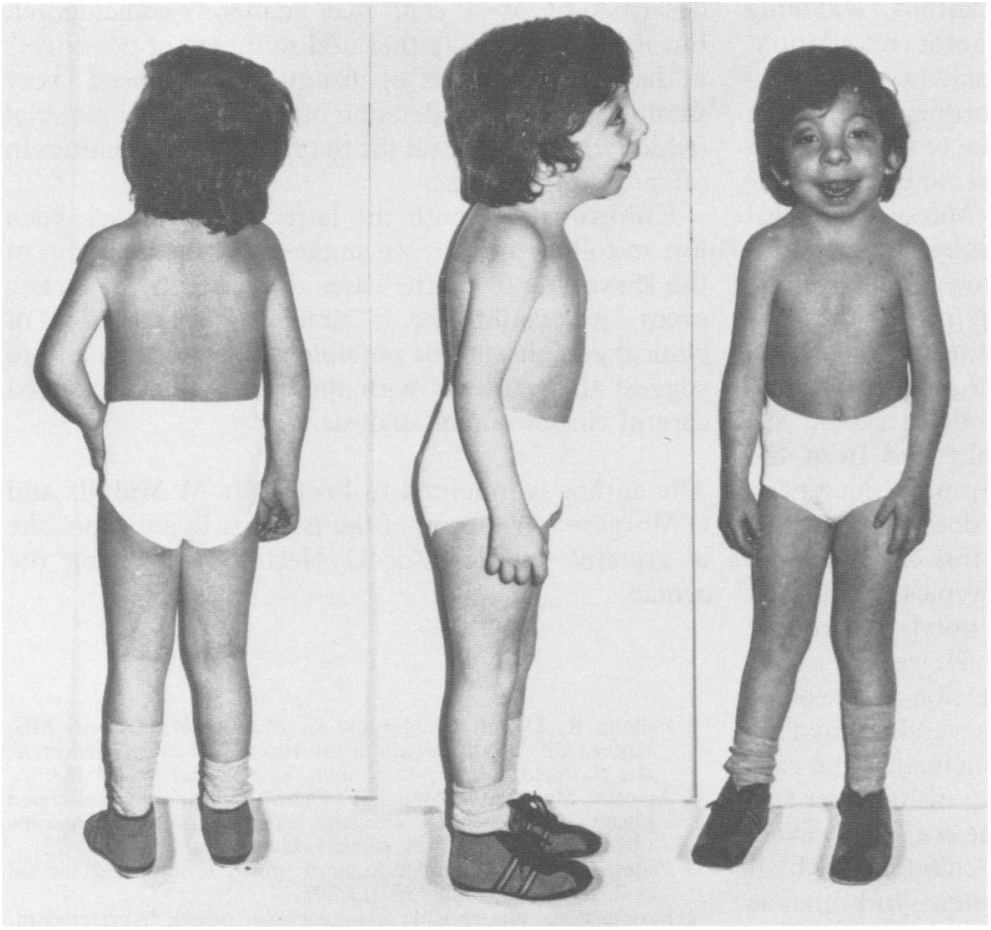

The proband. Note the metopic ridge, low posterior hairline, short neck, pterygium, and pectus excavatum. The facies is reminiscent of an Etruscan helmet.

Comparison of present case with previously reported cases.

\begin{tabular}{|c|c|c|c|c|c|}
\hline & \multicolumn{3}{|c|}{ Baraitser and Winter ${ }^{4}$} & \multirow[b]{2}{*}{ Ayme $e t a l^{2}$} & \multirow{2}{*}{$\begin{array}{l}\text { Present } \\
\text { case }\end{array}$} \\
\hline & Case 1 & Case 2 & Case 3 & & \\
\hline $\begin{array}{l}\text { Age at presentation } \\
\text { Sex } \\
\text { Parental consanguinity } \\
\text { Weight at birth (g) } \\
\text { Widening of the fontanelles } \\
\text { Metopic ridge } \\
\text { Ptosis } \\
\text { Oedematous upper eyelid } \\
\text { Hypertelorism } \\
\text { Epicanthic folds } \\
\text { Coloboma } \\
\text { Bulbous nasal tip } \\
\text { Long philtrum } \\
\text { Large mouth/thin upper lip } \\
\text { Full cheeks } \\
\text { Pointed chin } \\
\text { Short neck } \\
\text { Pterygium } \\
\text { Low posterior hairline } \\
\text { Height } \\
\text { Weight } \\
\text { Head circumference } \\
\text { Delayed motor development } \\
\text { Mental retardation } \\
\text { Severe speech delay } \\
\text { Karyotype. }\end{array}$ & $\begin{array}{c}+ \\
+ \\
+ \\
\text { RL } \\
\bullet \\
\bullet \\
- \\
- \\
\text { 3rd centile } \\
\text { 25th centile } \\
\text { 25th centile } \\
+ \\
+ \\
+\end{array}$ & $\begin{array}{c}+ \\
\vdots \\
+ \\
\text { RL } \\
\vdots \\
\vdots \\
\vdots \\
- \\
- \\
\text { 3rd centile } \\
\\
+ \\
+ \\
+ \\
+ \\
\mathbf{N}\end{array}$ & $\begin{array}{c}7 \text { mth } \\
\mathbf{F} \\
3600 \\
+ \\
+ \\
+ \\
+ \\
+ \\
\mathrm{L} \\
\bullet \\
: \\
\vdots \\
+ \\
+ \\
+ \\
\text { 3rd centile } \\
\text { 10th centile } \\
+ \\
+ \\
\stackrel{+}{\mathbf{N}}\end{array}$ & $\begin{array}{l}\text { 3rd centile } \\
\text { 3rd centile } \\
+ \\
\underset{(p)}{46, X}\end{array}$ & $\begin{array}{l}6 \mathbf{y} \\
\mathbf{M} \\
- \\
3100 \\
+ \\
+ \\
+ \\
+ \\
+ \\
+ \\
\mathbf{R L} \\
+ \\
+ \\
+ \\
+ \\
+ \\
+ \\
+ \\
+ \\
\text { 3rd centile } \\
\text { 3rd centile } \\
\text { 3rd centile } \\
+ \\
+ \\
+ \\
\text { iv(2) }\end{array}$ \\
\hline
\end{tabular}

- Characteristics observed from photographs. 
shaped facies, hypertelorism, epicanthus, widening of the fontanelles, and marked motor retardation. Mental development appeared satisfactory. Unfortunately, it was not possible to gain further information either about the presence of coloboma, or an evaluation of mental and speech development since the latter patient was lost to follow up (Mattei, personal communication). However, on photographic examination, there is evidence of oedematous upper eyelids, broad nasal tip, full cheeks, long philtrum, large mouth with thin upper lip, and pointed chin (table). His karyotype was $46, \mathrm{XY}, \operatorname{inv}(2)$ (p12q14), identical to that of the present patient. In both cases, the chromsomal rearrangement was inherited from the mother, who was phenotypically normal. Since pericentric inversion of chromosome 2 does not cause an abnormal phenotype, ${ }^{1}$ we feel that this chromosomal anomaly, inherited from phenotypically normal mothers, does not allow any phenotype-karyotype correlation in these two children. However, it has been reported that pericentric inversion of chromosome 2 causes repeated abortions, several anomalies, and mental retardation. ${ }^{1256}$ In conclusion, the case reported here is similar to the patients of Baraitser and Winter, ${ }^{4}$ and also to the case of Aymé et al. ${ }^{2}$ However, in the latter patient there was no coloboma, which may be an inconstant feature of this new syndrome, as it was only found on one side in one of the cases reported by Baraitser and Winter, ${ }^{4}$ as in Lenz syndrome. ${ }^{7}$

The inheritance suggested in this syndrome is autosomal recessive, since cases 1 and 2 reported by Baraitser and Winter ${ }^{4}$ were brothers.

The interesting finding of the same chromosomal rearrangement in the present case and in the child described by Aymé et $\mathrm{al}^{2}$ may be merely coincidental, but it is also possible that odd numbers of crossovers in the 'inversion loops' of chromosome 2 caused a very small duplication or deletion of chromosomal material (which may be a reason for the risk of abnormalities in offspring of carriers).

Unfortunately, both the latter patients have been lost to follow up, but we suggest a re-examination of the karyotype of all the cases discussed here. In any event, we would like to draw to the attention of clinical geneticists this possible new syndrome and to suggest that patients with these characteristics need careful chromosomal analysis.

The author is indebted to Professors M Midulla and $G$ Morgese for referral of the patient. In addition, she is grateful to Professor G Neri for reviewing the article.

1 Pallotta R, Dalprà L, Morgese G, Midulla M, Tibiletti MG, Nocera GF. Su di un caso di inversione pericentrica del cr. 2 . Riv Siciliana Med Prenat Neonat Pediatr Genet 1983;4:183.

2 Aymé S, Mattei MG, Mattei JF, Giraud F. Abnormal childhood phenotypes associated with the same balanced chromosome rearrangements as in the parents. Hum Genet 1979;48:7-12.

3 Pallotta $\mathbf{R}$. Una nuova sindrome a probabile localizzazione sul cr 2. Riv Ital Pediatr 1987;13:207.

4 Baraitser M, Winter RM. Iris coloboma, ptosis, hypertelorism, and mental retardation: a new syndrome. $\mathcal{f}$ Med Genet 1988;25:41-3.

5 Kleczkowska A, Fryns JP, Van den Berghe H. Pericentric inversions in man: personal experience and review of the literature. Hum Genet 1987;75:333-8.

6 Baccichetti C, Lenzini E, Peserico A, Tenconi R. Study on segregation and risk for abnormal offspring in carriers of pericentric inversion of the (pl1-q13) segment of chromosome 2. Clin Genet 1980;18:402-7.

7 Pallotta R. The Lenz microphthalmia syndrome. Ophthalmic Paediatr Genet 1983;3:103-7. 